\title{
Blood collection from the cranial vena cava of the ferret
}

The domestic ferret, though not as common a laboratory animal as the rat or mouse, serves as a model in critical research areas, including influenza biology and vaccine development. Studies involving ferrets necessitate knowledge of proper blood collection methods, such as cranial vena cava puncture.

Techniques for blood collection from the ferret (Mustela putorius furo) include puncture of the saphenous vein, cephalic vein, jugular vein, ventral coccygeal artery, femoral artery, orbital sinus, and heart ${ }^{1-6}$. Venipuncture of the cranial vena cava (CVC) is one of the best techniques for quick and safe collection of relatively large samples of blood in the ferret ${ }^{4}$. The method involves a 'blind stick' that is accomplished by familiarity with anatomic landmarks and good restraint of the ferret.

\section{ANATOMY AND PHYSIOLOGY}

The CVC in the ferret has a diameter of $3.0-3.5 \mathrm{~mm}$ and is the main vessel located cranial to the heart. The external and internal jugular veins are joined by the subclavian vein, which enters the right atrium of the heart as the cranial vena cava (Fig. $\mathbf{1}$ ).

The blood volume of the ferret is approximately $5-6 \%$ of its total body weight. Ten percent of the calculated blood volume may be safely collected at any one time. A cumulative collection of more than $20 \%$ of the total blood volume is not recommended for any two-week period ${ }^{6-8}$.

\section{RESTRAINT}

Restraint is usually not a problem in sick ferrets, but healthy ferrets can wriggle excessively and/or bite unless restrained by an experienced individual. It can be difficult to decide whether chemical or physical restraint is necessary, as chemical restraint can have complicating side-effects. For example, isoflurane anesthesia causes a rapid decrease in all hematological variables because it instigates splenic sequestration of erythrocytes (though this can be partially reversed by phenylephrine infusion or termination of anesthesia ${ }^{9,10}$ ). In studies that do not require fasting, ferrets may

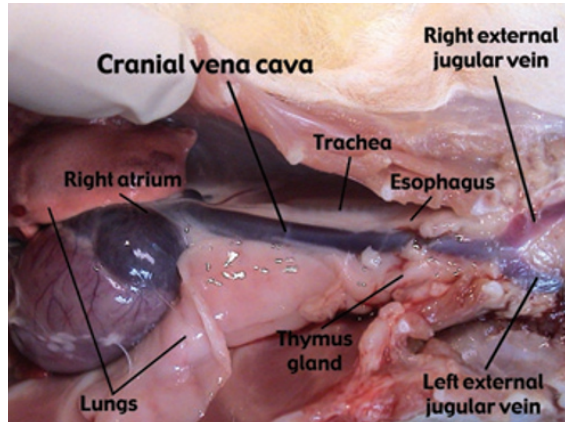

FIGURE 1 | Dissection of the cranial thorax, thoracic inlet, and neck of an adult ferret showing the cranial vena cava and its anatomic relationship with other intrathoracic organs. The cranial vena cava originates from the confluence of the external jugular veins and enters the right atrium of the heart. (Reprinted with permission from Capello, V., Exotic DVM, 8(3), 51-55 (2006).)

be distracted during manual restraint with Nutri-Cal (EVSCO Pharmaceuticals, Buena, $\mathrm{NJ}$ ), a corn syrup- and cane molasses-based nutritional supplement.

\section{COLLECTION METHODS}

Venipuncture of the cranial vena cava without anesthesia usually requires one phlebotomist and one or two individuals for restraint. The ferret may be tightly rolled in a towel and placed in dorsal recumbency. With two assistants, the ferret is placed in dorsal recumbency, one individual takes

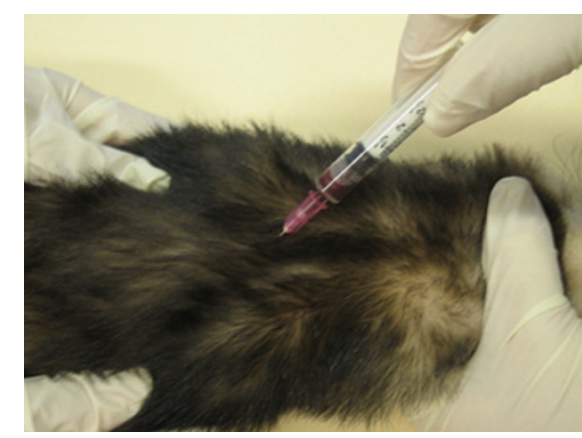

FIGURE 2 | Ferret in dorsal recumbency, under restraint for cranial vena cava puncture with 25 guage needle inserted at a $45^{\circ}$ angle and aimed towards the opposite hind leg. The phlebotomist is restraining the head; a technician is restraining the forelimbs and torso.

\section{EOUIPMENT FOR CVC PUNCTURE}

$1 \mathrm{ml}$ or $3 \mathrm{ml}$ syringe

25-gauge needles

Collection tubes

Towel for restraint
Optional equipment/supplies Isoflurane or other anesthetic Clippers Nutri-Cal control of the torso and caudal body and the other restrains the forearms and the head. If only one assistant is available, the phlebotomist may choose to restrain the head while the assistant 'scruffs' the ferret (grasping the ferret by the skin of the back of the neck) and restrains the forearms. It is critical that the ferret be firmly and symmetrically restrained.

Cranial vena cava venipuncture is a 'blind' technique; visualization of anatomical landmarks and correct angle placement of the needle are essential for success. If preferred, 


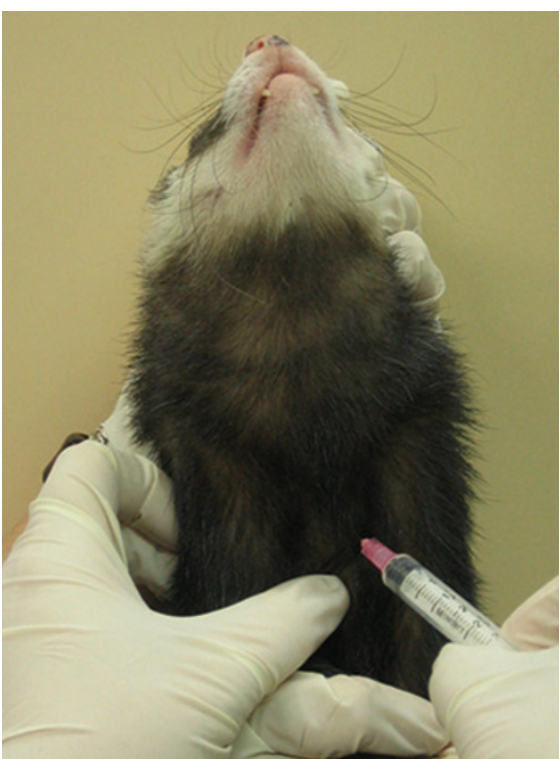

FIGURE 3 | Demonstration of the hanging ferret venipunture technique. Note the handler is 'scruffing' the ferret while controlling the forelimbs.

the fur can be shaved from the ventral portion of the neck. A 25-gauge needle attached to a 1 or $3 \mathrm{ml}$ syringe is inserted just lateral of the manubrium and cranial to the first rib. The needle is held at a $45^{\circ}$ angle and directed toward the opposite hind limb (Fig. 2). Gentle negative pressure (suction) is applied to the syringe as it is inserted to the hub. Often, blood will begin to flow into the syringe as the needle is inserted. If this does not occur, continue to apply negative pressure while slowly withdrawing the needle; the hub of the needle or syringe must be constantly monitored for the presence of blood. When the correct location is found, hold the needle steady and pull back on the plunger until the desired sample volume is obtained.

This technique can also be performed while 'scruffing' the ferret and allowing its body to hang. The holder keeps the front limbs down to prevent the ferret from interfering with the venipuncture; a second holder may be required to stabilize the hips if the ferret is especially fractious. The manubrium and the point of the shoulder are palpated. The phlebotomist then directs a 25-gauge needle (attached to a syringe) perpendicular to the ferret between the palpated sites and applies gentle negative pressure as the needle is advanced (Fig. 3). This is a 'blind stick,' and as a result, the venipuncture site may be either the jugular vein at the thoracic inlet just proximal to the jugular's junction with the CVC or the CVC itself.

During either technique, if the ferret struggles, remove the needle quickly and allow the ferret to become calm before making any additional collection attempts; consider anesthesia if the ferret continues to struggle. It is not necessary to apply direct pressure to the venipuncture site after the sample is obtained because the vessel is deep and encased in bony thoracic structures.

\section{Potential complications}

The cranial vena cava sampling technique described here is generally considered a safe, effective, and acceptable method for blood collection in the ferret. Nevertheless, excessive bleeding, sepsis, hemothorax, and damage to other intrathoracic structures are rare complications ${ }^{11}$. On occasion, air may be aspirated into the syringe as a result of insertion into the trachea; this is rarely associated with adverse effects. Although occurring infrequently, laceration of the vena cava, hemorrhage, and subsequent death are possible serious risks associated with this technique. Ferrets with undiagnosed thoracic disease may not tolerate the handling associated with this procedure ${ }^{12}$. Experienced technicians frequently perform this technique without anesthesia. Appropriate needle size and safe restraint minimize complications.

1. Moran, M. Intravenous injection and blood sampling in the ferret. J. Inst. Anim. Tech. 30 (1), 45-46 (1979).

2. Fox, J.G., Hewes, K. \& Niemi, S.M. Retro-orbital technique for blood collection from the ferret (Mustela putorius furo). Lab. Anim. Sci. 34(2), 198-199 (1984).

3. Otto, G., Rosenblad, W. \& Fox, J.G. Practical venipuncture in the ferret. Lab. Anim. Sci. 40(5), 565 (1990).

4. Hem, A., Smith, A.J. \& Solberg, P. Saphenous vein puncture for blood sampling of the mouse, rat, hamster, gerbil, guineapig, ferret and mink. Lab. Anim. 32(4), 364-368 (1998).

5. Murray, M.J. in Laboratory Medicine: Avian and Exotic Pets (ed. Fudge, A.M.) 266 (Saunders, Philadelphia, PA, 2000).

6. Marini, R.P., Otto, G., Erdman, S., Palley, L. \& Fox, J.G. in Laboratory Animal Medicine (eds. Fox, J.G., Anderson, L.C., Loew, F.M. \& Quimby, F.W.) 483-517 (Academic Press, London, 2002).

7. Schoemaker, N.J. Ferrets. in BSAVA Manual of Exotic Pets (eds. Meredith, A. \& Redrobe, S.) 93-101 (British Small Animal Veterinary Association, Quedgeley, 2002).

8. Fox, J.G. Biology and Diseases of the Ferret 345 (Lea \& Febiger, Philadelphia, 1988).

9. Marini, R.P. et al. Distribution of technetium $99 \mathrm{~m}$-labelled red blood cells during isoflurane anesthesia in ferrets. Am. J. Vet. Res. 58(7), 781-785 (1997).

10. Marini, R.P. et al. Effect of isoflurane on hematologic variables in ferrets. Am. J. Vet. Res. 55(10), 1479-1483 (1994).

11. Capello, V. Application of the cranial vena cava venipuncture technique to small exotic mammals. Exotic DVM 8(3), 51-55 (2006).

12. Rosenthal, K. Ferret venipuncture. NAVC Clin Brief 1(11), 62-65 (2003).

LAB ANIMAL welcomes reader contributions to "Clinical Techniques". Submissions should include up to three illustrations or photos and a list of equipment needed to perform the procedure described. Please email manuscripts to editors@labanimal.com. Selections are made on the basis of relevance and interest to readers. Please refer to the Guide to Authors for information on submission of digital figures. 